\title{
Royal Jelly Attenuates LPS-Induced Inflammation in BV-2 Microglial Cells through Modulating NF- $\kappa$ B and p38/JNK Signaling Pathways
}

\author{
Meng-Meng You, ${ }^{1}$ Yi-Fan Chen, ${ }^{1}$ Yong-Ming Pan, ${ }^{1,2}$ Yi-Chen Liu, ${ }^{1}$ Jue Tu, ${ }^{2}$ Kai Wang $\mathbb{D},{ }^{3}$ \\ and Fu-Liang $\mathrm{Hu}\left(\mathbb{C}^{1}\right.$ \\ ${ }^{1}$ College of Animal Sciences, Zhejiang University, Hangzhou 310058, China \\ ${ }^{2}$ Comparative Medical Research Center, Experimental Animal Research Center, Zhejiang Chinese Medical University, \\ Hangzhou 310053, China \\ ${ }^{3}$ Institute of Apicultural Research, Chinese Academy of Agricultural Sciences, Beijing 100093, China
}

Correspondence should be addressed to Fu-Liang Hu; flhu@zju.edu.cn

Received 18 October 2017; Revised 5 February 2018; Accepted 8 March 2018; Published 8 April 2018

Academic Editor: Tânia Silvia Fröde

Copyright (c) 2018 Meng-Meng You et al. This is an open access article distributed under the Creative Commons Attribution License, which permits unrestricted use, distribution, and reproduction in any medium, provided the original work is properly cited.

Royal jelly (RJ), a hive product with versatile pharmacological activities, has been used as a traditional functional food to prevent or treat inflammatory diseases. However, little is known about the anti-inflammatory effect of RJ in microglial cells. The aim of this study is to assess the anti-inflammatory effects of RJ in lipopolysaccharide- (LPS-) induced murine immortalized BV-2 cells and to explore the underlying molecular mechanisms. Our results showed that in LPS-stimulated BV-2 cells, RJ significantly inhibited iNOS and COX-2 expression at mRNA and protein levels. The mRNA expression of IL-6, IL- $1 \beta$, and TNF- $\alpha$ was also downregulated by RJ in a concentration-dependent manner. Additionally, RJ protected BV-2 cells against oxidative stress by upregulating heme oxygenase-1 (HO-1) expression and by reducing reactive oxygen species (ROS) and nitric oxide (NO) production. Mechanistically, we found that RJ could alleviate inflammatory response in microglia by suppressing the phosphorylation of $\mathrm{I} \kappa \mathrm{B} \alpha, \mathrm{p} 38$, and JNK and by inhibiting the nucleus translocation of NF- $\kappa \mathrm{B}$ p 65 . These findings suggest that RJ might be a promising functional food to delay inflammatory progress by influencing the microglia function.

\section{Introduction}

It is noteworthy that inflammation in the central nervous system (CNS) is associated with the occurrence and progression of some neurodegenerative diseases, including Alzheimer's disease (AD) [1]. Since Eikelenboom and Stam first found the inflammatory mediators in AD brains after 1982, more and more scientists started to explore the relationship between inflammation and AD [2]. At the end of the 1980s, McGeer and Rogers reported that there were lots of activated glia cells in the $\mathrm{AD}$ brain $[3,4]$. An elevated level of interleukin-18 (IL-18), a detrimental inflammatory cytokine, has also been reported in the brains of AD patients [5]. Since the proposal of the concept "neuroinflammation," it is now well accepted that one of the most important pathogeneses of $\mathrm{AD}$ is chronic long-lasting neuroinflammation [6].
Microglia, a type of resident macrophages located in the brain, is the major homeostasis regulator of CNS [7]. Under normal physiological conditions, microglia can upregulate anti-inflammatory mediators and phagocytose the toxic cellular debris with high efficiency. In spite of this, the neuron growth factor (NGF) secreted by microglia is a trophic factor for neurons $[8,9]$. However, microglia will switch to an activated phenotype (M1 type) and generate highly detrimental mediators when their microenvironment becomes stressful. All of these neurotoxic mediators will do harm to neurons and glial cells, and the brain homeostasis will be disturbed, which is the main cause of most neurodegenerative diseases [10]. Due to the dual effects of microglia, appropriate activation of microglia is needed to keep the brain away from endogenous or exogenous toxins. It was reported that lipopolysaccharide (LPS), a bacterial endotoxin, could stimulate 
microglia to M1 type by combining with its receptors and activating inflammatory and oxidative pathways [11]. Systemic administration of LPS is known to have an influence on neurobiological conditions, promoting the production of inflammatory factors [12]. In studies with cell cultures, inflammation of BV-2 cell line and primary microglia is frequently modeled by LPS [13-15]. Therefore, in this study, we employed LPS as stimuli to induce inflammatory damage in BV-2 cells. The production of proinflammatory and cytotoxic mediators by microglia, such as IL-6, nitric oxide (NO), reactive oxygen species (ROS), inducible nitric oxide synthase (iNOS), IL- $1 \beta$, cyclooxygenase-2 (COX-2), and tumor necrosis factor- $\alpha$ (TNF- $\alpha$ ), will be significantly elevated after LPS treatment [16]. In addition, mounting evidence has shown that LPS can cause inflammation via regulating the activity of nuclear factor kappa $\mathrm{B}(\mathrm{NF}-\kappa \mathrm{B})$, mitogen-activated protein kinases (MAPK), signal transducer and activator of transcription 1 (STAT1), and activator protein (AP-1) [17-19].

To improve neurodegenerative disorders, diverse treatment modalities were adopted to reduce inflammation caused by microglia. Nonsteroidal anti-inflammatory drugs (NSAIDs) are a class of drugs used to treat inflammation, mild to moderate pain, and fever, block the COX enzymes, and reduce the production of prostaglandins throughout the body [20]. Some studies have already reported that long-term administration of NSAIDs was capable of attenuating neuroinflammation and improving tau pathology in transgenic AD mice [21]. However, NSAIDs may increase the risk of developing gastrointestinal and cardiovascular diseases, which greatly limits their range of application [22, 23]. Nowadays, a growing number of studies have focused on the antineuroinflammatory effects of natural functional foods $[24,25]$. Royal jelly (RJ), a bee product produced by the hypopharyngeal and mandibular glands of worker bees, is chemically composed of water, proteins, carbohydrates, vitamins, lipids, and other bioactive compounds [26]. As a functional food, RJ has various pharmacological activities, including anti-inflammatory [27], antihypertensive [28], antioxidative [29], and memory function restoration activities [30]. However, whether RJ could protect microglial cells from inflammatory stimuli remains elusive. Here, the aim of this study is to assess the influence of RJ on the function of BV-2 cells under LPS-induced inflammatory conditions in vitro and to further explore the underlying mechanisms.

\section{Materials and Methods}

2.1. Chemicals and Reagents. RJ was purchased from Fengzhiyu Apicultural Co. Ltd. (Hangzhou, China). The purity of $\mathrm{RJ}$ is $100 \%$, and its composition is in line with international standards (ISO12824: 2016). RJ was suspended in sterile phosphate-buffered saline (PBS) at concentration of $20 \mathrm{mg} /$ $\mathrm{mL}$, and RJ stock solution was stored at $-20^{\circ} \mathrm{C}$ until use. LPS (Escherichia coli O111: B4), 2',7'-dichlorofluorescein diacetate (DCFH-DA) and alkaline phosphatase-conjugated antibody (anti-rabbit IgG) were purchased from Sigma (St. Louis, MO, USA). Fetal bovine serum (FBS) was purchased from Gibco BRL (Grand Island, NY, USA). Cell counting kit-8 was purchased from Dojindo (Japan). Griess reagent, $\mathrm{NaNO}_{2}$, and 4'6-diamidino-2-phenylindole (DAPI) were purchased from Sangon Biotechnology, Co. Ltd. (Shanghai, China). ELISA kits for IL- 6 and TNF- $\alpha$ were purchased from Neobioscience (Shanghai, China). PrimeScript RT Master Mix real-time kits were purchased from Takara (Dalian, China). Primary antibodies against NF- $\kappa \mathrm{B}$ p $65, \mathrm{I} \kappa \mathrm{B} \alpha, \mathrm{COX}-$ 2 , and iNOS were purchased from Abcam (Cambridge, Massachusetts, USA). Primary antibodies against $\mathrm{p}-\mathrm{I} \kappa \mathrm{B} \alpha$, JNK, $\mathrm{p}-$ JNK, p38, p-p38, ERK, and p-ERK were purchased from Cell Signaling Technology (Danvers, MA, USA).

2.2. Cell Culture. The murine microglial cell line BV-2 was a generous gift from Professor Yunbi Lu (School of Medicine, Zhejiang University, China). BV-2 cells were cultured in high-glucose DMEM supplemented with 10\% FBS, $2 \mathrm{mM}$ glutamine, $100 \mathrm{U} / \mathrm{mL}$ penicillin, and $100 \mu \mathrm{g} / \mathrm{mL}$ streptomycin at $37^{\circ} \mathrm{C}$ in a $5 \% \mathrm{CO}_{2}$ atmosphere. After reaching $80 \%-$ $90 \%$ confluency, BV-2 cells were seeded into plates for $24 \mathrm{~h}$ incubation in high-glucose DMEM supplemented with $10 \%$ FBS. The cell culture medium was then removed and washed 3 times with PBS. After that, RJ stock solution was diluted into desired concentrations using serum-free medium, and the cells were pretreated with a mixture of RJ and serumfree medium for $1 \mathrm{~h}$ followed by addition of LPS $(1 \mu \mathrm{g} / \mathrm{mL})$. The incubation period of LPS varies depending on the experiment.

2.3. Cell Viability Assay. The neurotoxicity effect of RJ was measured by cell counting kit- 8 assay according to the manufacturer's instruction. BV-2 cells were seeded into 96-well plates for $24 \mathrm{~h}$ and were then incubated with different concentrations of RJ $(0,0.3,1,3$, and $6 \mathrm{mg} / \mathrm{mL})$ for another $24 \mathrm{~h}$. Following that, the cells were incubated with $10 \mu \mathrm{L}$ cell counting kit- 8 solution for $2 \mathrm{~h}$ at $37^{\circ} \mathrm{C}$. The percentage of surviving cells was measured using microplate reader (Bio-Rad, Model 550, CA) at $450 \mathrm{~nm}$.

2.4. Determination of NO Production. The amount of nitrite accumulation in the culture medium of BV-2 cells was measured using Griess reagent. BV-2 cells were plated in 24-well plates for $24 \mathrm{~h}$. After that, cells were treated with RJ $(0,0.3,1$, and $3 \mathrm{mg} / \mathrm{mL})$ for $1 \mathrm{~h}$ prior to $24 \mathrm{~h}$ LPS $(1 \mu \mathrm{g} / \mathrm{mL})$ stimulation. After the collection of culture medium, the supernatant absorbance was determined at $540 \mathrm{~nm}$ using a microplate absorbance reader. Nitrite concentrations were calculated according to nitrite standard curve.

2.5. Reactive Oxygen Species Detection. The ROS assay in BV2 cells was carried out as described before with some minor modifications [31]. Cells were seeded into 12-well plates for $24 \mathrm{~h}$ incubation, and then various concentrations of RJ ( 0 , $0.3,1$, and $3 \mathrm{mg} / \mathrm{mL}$ ) were added to the plates for $1 \mathrm{~h}$ followed by LPS $(1 \mu \mathrm{g} / \mathrm{mL})$ treatment. After $24 \mathrm{~h}$ incubation, $10 \mu \mathrm{M}$ (final concentration) DCFH-DA (a sensitive fluorescent probe) was added to each well for $30 \mathrm{~min}$ at $37^{\circ} \mathrm{C}$. After that, the cells were detached with trypsin and washed with PBS for three times by centrifugation. The production of ROS was measured by BD FACSCalibur flow cytometer at emission and excitation wavelengths of 535 and $488 \mathrm{~nm}$. 
2.6. RNA Extraction and Quantitative Real-Time PCR. In order to measure the mRNA expression of inflammatory mediators in BV-2 microglial cells, total RNA from BV-2 cells was isolated using RNA extraction kits (Aidlab Biotechnologies Co. Ltd., Beijing, China) and was quantified by NanoDrop spectrophotometer (ND-2000, NanoDrop Technologies, USA). For reverse transcription, 500 nanograms of total RNA of each sample was reverse transcribed into cDNA using PrimeScript RT Master Mix (TaKaRa, Dalian, China). After cDNA synthesis, quantitative real-time PCR was conducted using a Master cycle reprealplex (Eppendorf, Hamburg, Germany) with a SYBR Premix Ex Taq (TaKaRa, Dalian, China) via a standard two-step PCR reaction according to the manufacturer's instruction. The mRNA expression of IL-6, iNOS, COX-2, TNF- $\alpha$, heme oxygenase-1 (HO-1), monocyte chemotactic protein 1 (MCP-1), and IL- $1 \beta$ was normalized to GAPDH. The primer sequences used in this study are listed in Table 1.

2.7. Cytokine Assay (ELISA Assay). The protein levels of IL-6 and TNF- $\alpha$ in culture medium were quantified by enzymelinked immunosorbent assay (ELISA) kits. BV-2 cells were pretreated with RJ $(0.3,1$, and $3 \mathrm{mg} / \mathrm{mL})$ for $1 \mathrm{~h}$ and were then exposed to LPS $(1 \mu \mathrm{g} / \mathrm{mL})$ for $24 \mathrm{~h}$. Cell-free supernatants were collected and tested according to manufacturer's protocols. Briefly, supernatants were added to microplate wells, which were coated with specific antibodies in advance. After $1.5 \mathrm{~h}$ of incubation at $37^{\circ} \mathrm{C}$, unbound substances were washed away, and enzyme-linked antibody was added to each well followed by $1 \mathrm{~h}$ incubation at $37^{\circ} \mathrm{C}$. Then, the second wash was carried out to remove unbound antibodyenzyme reagents. Finally, the substrate solution was pipetted into each well for $15 \mathrm{~min}$, and the stop solution was added to end the color development. Absorbance at $450 \mathrm{~nm}$ was measured using a microplate reader.

2.8. Immunofluorescence Staining. For the detection of NF$\kappa \mathrm{B}$ nuclear translocation, BV-2 cells were pretreated with $\mathrm{RJ}$ $(0.3,1$, and $3 \mathrm{mg} / \mathrm{mL})$ for $1 \mathrm{~h}$ and were subsequently incubated by $1 \mu \mathrm{g} / \mathrm{mL}$ LPS for $45 \mathrm{~min}$. After that, BV-2 cells were fixed with precooled $4 \%$ paraformaldehyde, permeabilized with $0.3 \%$ Triton $\mathrm{X}-100$, and blocked with $5 \%$ bovine serum albumin (BSA) for $30 \mathrm{~min}$, respectively. Then, the monoclonal primary antibody to NF- $\kappa$ B p65 $(1: 250)$ was applied overnight at $4^{\circ} \mathrm{C}$, followed by incubation with Alexa Fluor 488-conjugated goat anti-rabbit IgG $(1: 250)$ for $1 \mathrm{~h}$ at $37^{\circ} \mathrm{C}$ in dark. At last, BV-2 cells were stained with DAPI for $5 \mathrm{~min}$ at room temperature, and after being washed three times with PBS, the cells were examined under a confocal laser microscope (Leica, TCS SP5, Germany).

2.9. Cellular Protein Extraction and Western Blot Analysis. The Western blot analysis was conducted according to protocols described previously [32]. Briefly, after different treatments, BV-2 cells were washed with precooled PBS twice, and cytoplasmic proteins were lysed with NP-40 which has already been added with a protease/phosphatase inhibitor cocktail (Roche, Basel, Switzerland) in advance. The cells were then collected, and bicinchoninic acid (BCA) assay was conducted to assess the protein concentration using BCA protein assay kit (Weiao Biotechnology, Shanghai, China). Degenerated proteins $(30 \mu \mathrm{g})$ were separated by $12 \%$ sodium dodecyl sulphate-polyacrylamide gel electrophoresis (SDS-PAGE) and were then transferred onto polyvinylidene difluoride (PVDF) membranes (Millipore, Billerica, MA). PVDF membranes were blocked with 5\% skim milk at room temperature for $1 \mathrm{~h}$ to avoid nonspecific binding, and immunoblots were incubated for overnight at $4^{\circ} \mathrm{C}$ with primary antibodies that specifically detect $\mathrm{I} \kappa \mathrm{B} \alpha, \mathrm{p}-\mathrm{I} \kappa \mathrm{B} \alpha, \mathrm{JNK}, \mathrm{p}-\mathrm{JNK}, \mathrm{p} 38, \mathrm{p}-\mathrm{p} 38, \mathrm{ERK}, \mathrm{p}-$ ERK, COX-2, iNOS, and $\beta$-tubulin. After that, horseradish peroxidase-conjugated secondary antibodies were incubated for $1 \mathrm{~h}$ at room temperature. Blots were developed by NBT/BCIP, and band intensities were quantified using Quantity One Software.

2.10. Statistical Analysis. The data are expressed as means \pm SEM from three independent experiments. Oneway ANOVA with post hoc Tukey's test was used to determine statistical difference, and $P$ values $<0.05$ were considered statistically significant. Statistical analyses were performed using GraphPad Prism 6.0 (GraphPad Software Inc., La Jolla, CA, USA).

\section{Results}

3.1. Effect of RJ on BV-2 Cell Viability. To determine the appropriate concentrations of RJ treatments, we carried out the cell counting kit- 8 assay to measure the viability of cells treated by RJ alone and cells cotreated with RJ/LPS (Figure 1). Based on our cell viability histogram, treatments of RJ up to $3 \mathrm{mg} / \mathrm{mL}$ for $24 \mathrm{~h}$ had no cytotoxic effects in comparison with the control group. However, RJ at a dose of $6 \mathrm{mg} / \mathrm{mL}$ significantly reduced the viability of BV-2 cells either by itself or in combination with LPS $(P<0.01)$. According to these results, we chose RJ at a concentration of $0.3,1$, and $3 \mathrm{mg} / \mathrm{mL}$ in the following studies.

3.2. Effects of RJ on LPS-Induced Production of NO and ROS and Protein Expression of iNOS and COX-2 in BV-2 Cells. $\mathrm{NO}$ levels in cell culture medium were markedly elevated after $24 \mathrm{~h}$ of LPS treatment compared to the control group, whereas RJ significantly lowered this level at all three concentrations $(P<0.01)$ (Figure $2(\mathrm{a}))$. At $3 \mathrm{mg} / \mathrm{mL}$ of RJ, NO production was suppressed by more than $60 \%$ compared to the LPS treatment group. In addition, fluorescence-based ROS assay was carried out to assess the ROS production by BV-2 cells (Figure 2(b)). We found that preincubation of RJ for $1 \mathrm{~h}$ could suppress the increase of ROS levels caused by LPS in a dose-dependent manner. Western blot was used to assess the protein expression of iNOS and COX-2. As shown in Figures 2(c)-2(e), LPS treatment for $24 \mathrm{~h}$ evidently promoted the expression of iNOS and COX-2, while RJ pretreatment $(1 \mathrm{mg} / \mathrm{mL}$ and $3 \mathrm{mg} / \mathrm{mL})$ markedly suppressed these increases. However, RJ at a low concentration $(0.3 \mathrm{mg} / \mathrm{mL})$ did not work in this case.

3.3. Effects of RJ on LPS-Induced mRNA Expression of Inflammatory Mediators. The effect of RJ on LPS-induced 
TABLE 1: Primer sequence used in qRT-PCR.

\begin{tabular}{|c|c|c|c|c|}
\hline Gene & Forward primer & Reverse primer & $\begin{array}{l}\text { Product } \\
\text { size (bp) }\end{array}$ & $\begin{array}{c}\text { GenBank accession } \\
\text { number }\end{array}$ \\
\hline IL-6 & $5^{\prime}$-CTCTGCAAGAGACTTCCATCC-3' & $5^{\prime}$-GAATTGCCATTGCACAACTC-3' & 210 & NM_031168.1 \\
\hline iNOS & $5^{\prime}$-TTTCCAGAAGCAGAATGTGACC-3' & $5^{\prime}$-AACACCACTTTCACCAAGACTC-3' & 294 & NM_010927.3 \\
\hline $\mathrm{COX}-2$ & $5^{\prime}$-GAAATATCAGGTCATTGGTGGAG-3' & $5^{\prime}$-GTTTGGAATAGTTGCTCATCAC-3' & 237 & NM_011198.3 \\
\hline TNF- $\alpha$ & 5'-CCACGCTCTTCTGTCTACTG-3' & 5'-ACTTGGTGGTTTGCTACGAC-3' & 169 & NM_013693.2 \\
\hline $\mathrm{HO}-1$ & 5'-ACATTGAGCTGTTTGAGGAG-3' & $5^{\prime}$-TACATGGCATAAATTCCCACTG-3' & 241 & NM_010442.2 \\
\hline $\mathrm{MCP}-1$ & $5^{\prime}$-AAGAAGCTGTAGTTTTTGTCACCA-3' & $5^{\prime}$-TGAAGACCTTAGGGCAGATGC-3' & 155 & NM_011333.3 \\
\hline IL-1 $\beta$ & 5'-ATCTCGCAGCAGCACATCAAC-3' & 5'-TGTTCATCTCGGAGCCTGTAGT-3' & 239 & NM_008361.3 \\
\hline GAPDH & $5^{\prime}$-GAGAAACCTGCCAAGTATGATGAC-3' & $5^{\prime}$-TAGCCGTATTCATTGTCATACCAG-3' & 212 & NM_008084.2 \\
\hline
\end{tabular}

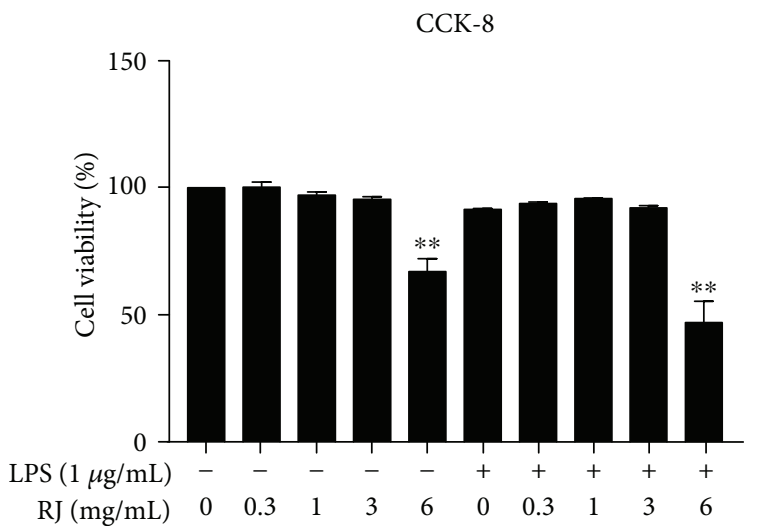

FIGURE 1: Cell viability of RJ-treated microglia was determined by cell counting kit- 8 assay. BV-2 cells were treated with $0,0.3,1,3$, and $6 \mathrm{mg} / \mathrm{mL} \mathrm{RJ}$ for $24 \mathrm{~h}$, respectively, and the results are expressed as proportions of surviving cells compared with controls. Data are presented as means \pm SEM, and group differences were analyzed by one-way ANOVA with post hoc Tukey's test. ${ }^{* *} P<0.01$ compared with untreated control group.

mRNA expression of iNOS, COX-2, IL-6, IL- $1 \beta$, TNF- $\alpha$, MCP-1, and HO-1 was analyzed by qRT-PCR (Figure 3). Our results showed that COX-2, iNOS, and MCP-1 mRNA expressions were significantly elevated in response to LPS induction for $6 \mathrm{~h}(P<0.01)$. In contrast, $1 \mathrm{~h}$ pretreatment of $3 \mathrm{mg} / \mathrm{mL}$ RJ markedly lowered these expressions $(P<0.01)$, though RJ did not downregulate the expression of COX-2 and MCP-1 at a concentration lower than $3 \mathrm{mg} / \mathrm{mL}$ (Figures 3(a)-3(c)). Regarding IL-6, IL-1 $\beta$, and TNF- $\alpha$, pretreatment with RJ for $1 \mathrm{~h}$ caused a concentration-dependent decrease of mRNA expression in BV-2 cells (Figures 3(d)3(f)). It was reported recently that $\mathrm{HO}-1$ could act as a target for treating neurodegenerative diseases [33]. The qRTPCR results showed that RJ could upregulate the expression of HO-1 significantly, whereas HO-1 expression in BV-2 cells pretreated by $3 \mathrm{mg} / \mathrm{mL}$ RJ before LPS stimulation was about 8 times higher than that of the control group. This demonstrates that RJ pretreatment could effectively inhibit the expression of key inflammatory mediators in LPSstimulated BV-2 cells.
3.4. Effects of RJ on LPS-Induced Cytokine Production. As shown in Figure 4, the production of proinflammatory cytokines such as IL-6 and TNF- $\alpha$ was strongly upregulated after $24 \mathrm{~h}$ treatment of LPS compared to the control group. On the other hand, RJ pretreatment inhibited this increase in a dosedependent manner, indicating that RJ could work efficiently to suppress the secretion of inflammatory mediators in LPS-induced BV-2 cells.

3.5. Effects of RJ on LPS-Induced Activation of NF- $\kappa B$ and p38/JNK Pathways. Our results showed that the phosphorylation levels of $\mathrm{I} \kappa \mathrm{B} \alpha, \mathrm{p} 38$, c-Jun $\mathrm{NH} 2$-terminal kinases (JNK), and extracellular signal-regulated kinases (ERK) peaked at 45 minutes after the LPS stimulation (Supplementary Figure 1). Thus, we chose $45 \mathrm{~min}$ as the LPS stimulation period. When $\mathrm{NF}-\kappa \mathrm{B}$ is activated, p65 subunit of $\mathrm{NF}-\kappa \mathrm{B}$ complex will translocate from cytoplasm to nucleus. From our immunocytochemistry results, it was evident that GFPlabeled NF- $\kappa \mathrm{B}$ p 65 submit was mainly located in cytoplasm under normal physiological conditions, and it translocated to nucleus when BV-2 cells were activated by $1 \mu \mathrm{g} / \mathrm{mL}$ LPS. However, RJ inhibited NF- $\kappa$ B p65 translocation under LPS exposure (Figure 5(a)). In addition, Western blot results revealed that LPS treatment $(1 \mu \mathrm{g} / \mathrm{mL})$ significantly promoted the $\mathrm{I} \kappa \mathrm{B} \alpha$ degradation, which was consistent with previous studies [34, 35]. RJ at all three concentrations could significantly inhibit the degradation of $\mathrm{I} \kappa \mathrm{B} \alpha$ and decrease the phosphorylation levels of $\mathrm{I} \kappa \mathrm{B} \alpha$ and $\mathrm{p} 38$ elevated by LPS treatment (Figures 5(b)-5(d)). Although RJ at $0.3 \mathrm{mg} / \mathrm{mL}$ did not inhibit the activation of JNK pathway, $1 \mathrm{mg} / \mathrm{mL}$ and $3 \mathrm{mg} / \mathrm{mL}$ RJ markedly lowered the protein expression of p-JNK (Figures 5(b) and 5(e)). The LPSinduced phosphorylation of p38 and JNK was also strongly inhibited by their inhibitors SB203580 and SP600125 (Supplementary Figure 2). These results suggest that RJ reduces the inflammatory response of $\mathrm{BV}-2$ microglia to LPS stimulation by inhibiting the phosphorylation of $\mathrm{I} \kappa \mathrm{B} \alpha$, p38, and JNK. The phosphorylation level of ERK was significantly increased after LPS treatment for $45 \mathrm{~min}$; however, RJ at all three concentrations do not have any effect on p-ERK level (Figures 5(b) and 5(f)). We speculate that ERK pathway may not be involved in the mechanism by which RJ exerts the anti-inflammatory effects in BV-2 cells. 


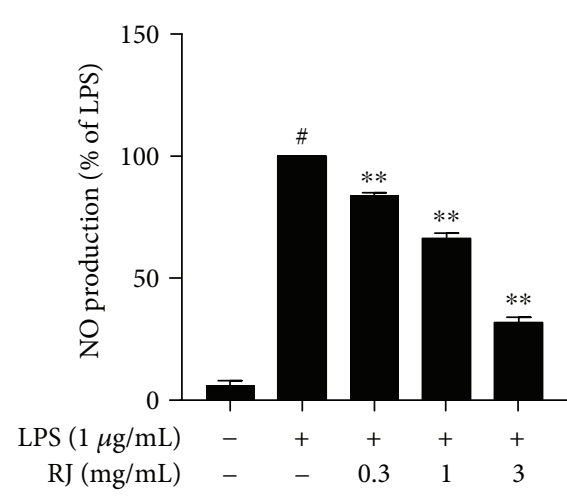

(a)

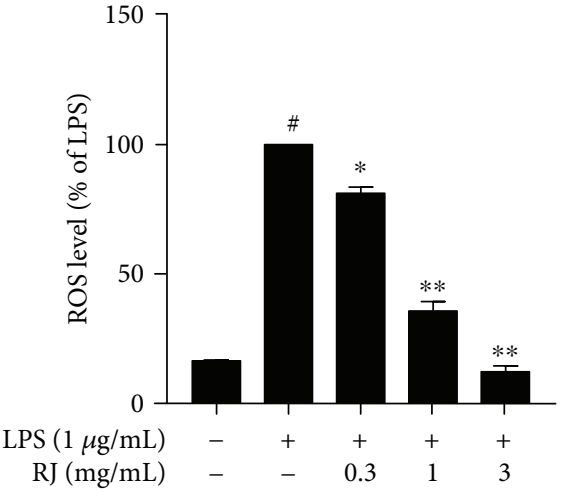

(b)

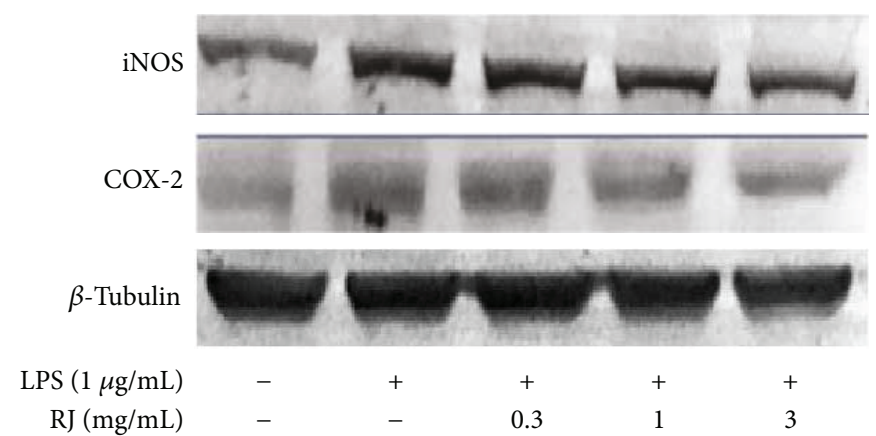

(c)

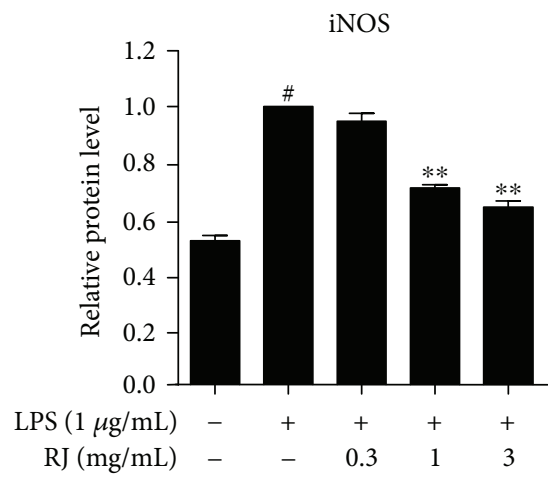

(d)

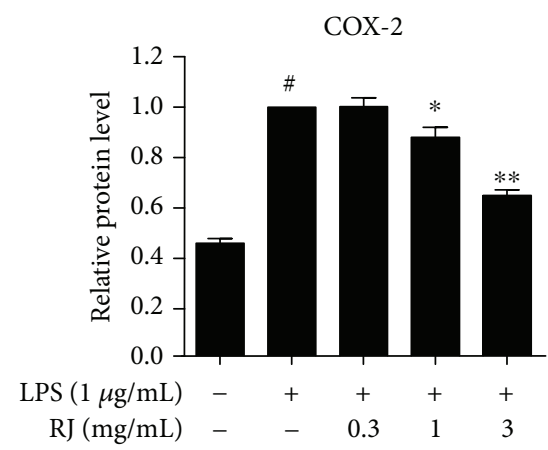

(e)

FIGURE 2: Effects of RJ on LPS-induced production of NO and ROS, as well as the protein expression of iNOS and COX-2 in BV-2 cells. BV-2 cells were pretreated with RJ $(0,0.3,1$, and $3 \mathrm{mg} / \mathrm{mL})$ for $1 \mathrm{~h}$, followed by 24 hours of incubation with LPS $(1 \mu \mathrm{g} / \mathrm{mL})$. The NO production in cell supernatants was detected by Griess reaction (a), and intracellular ROS levels were measured using DCF fluorescence as described in the text (b). BV-2 cells were pretreated in the same way as described above and were then stimulated with $1 \mu \mathrm{g} / \mathrm{mL}$ LPS for $24 \mathrm{~h}$. Proteins were extracted, and Western blot analysis was conducted using specific antibodies against iNOS and COX-2 (c-e). $\beta$-Tubulin protein was used here as an internal control. Data are presented as means \pm SEM, and group differences were analyzed by one-way ANOVA with post hoc Tukey's test. ${ }^{\#} P<0.05$ compared with untreated control group; ${ }^{*} P<0.05,{ }^{* *} P<0.01$ compared with the group treated with LPS alone.

\section{Discussion}

It is widely accepted that CNS inflammation in neurodegenerative diseases is a double-edged sword. It acts as an innate defense mechanism against various stimuli and removes toxic as well as other detrimental substances. However, it can also promote the neurodegenerative process if the inflammation is sufficiently severe [36]. Some studies have already verified that anti-inflammatory drugs, such as ibuprofen, could alleviate CNS inflammation and inhibit the activation of microglial cells $[37,38]$. Therefore, it is of great interest to investigate whether RJ, a natural functional food with considerable anti-inflammatory activities, could alleviate inflammation damage caused by microglial cells. In the present study, we used LPS at $1 \mu \mathrm{g} / \mathrm{mL}$ to treat BV-2 cells because our preliminary experimental results showed that $1 \mu \mathrm{g} / \mathrm{mL}$ of LPS could significantly cause inflammation without affecting cell viability (data not shown). In addition, previous studies have also used $1 \mu \mathrm{g} / \mathrm{mL}$ of LPS (Escherichia coli O111: B4) as inflammatory stimuli in BV-2 microglial cells [39]. We tested the anti-inflammatory effects of RJ in LPStreated BV-2 cells and provided firsthand evidence that RJ 


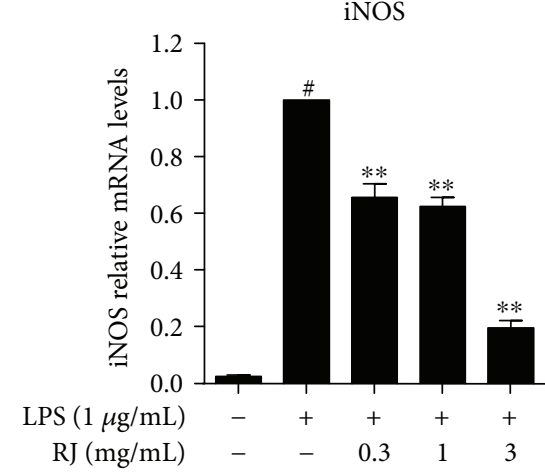

(a)

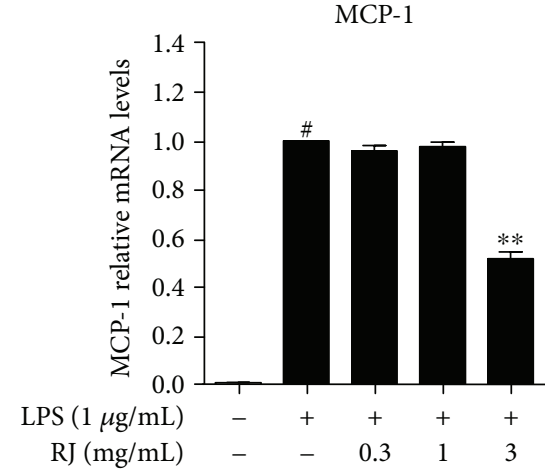

(c)

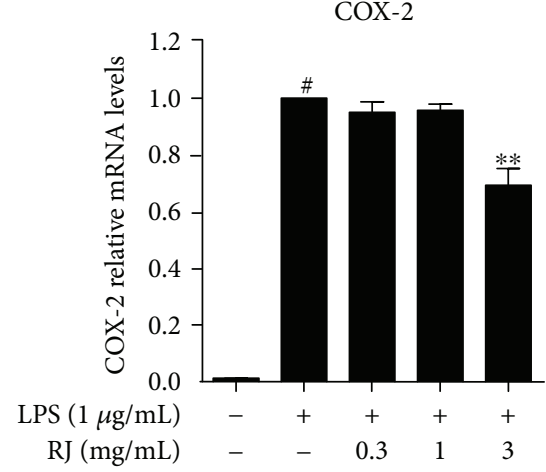

(b)

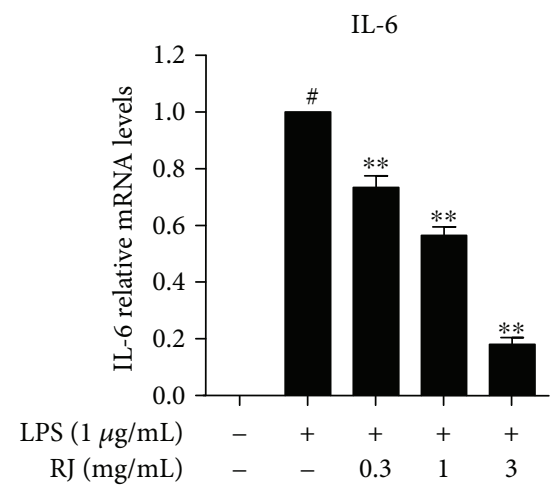

(d)

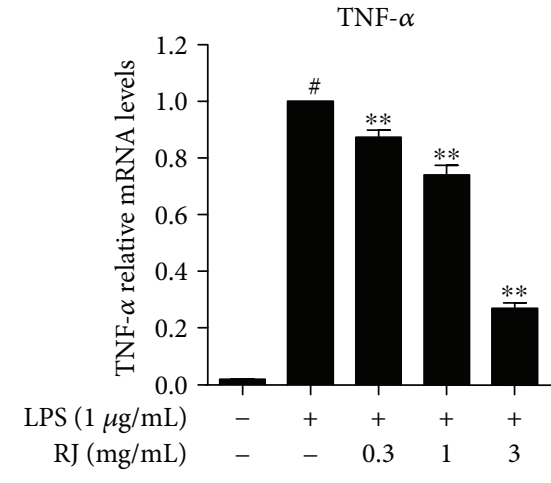

(e)

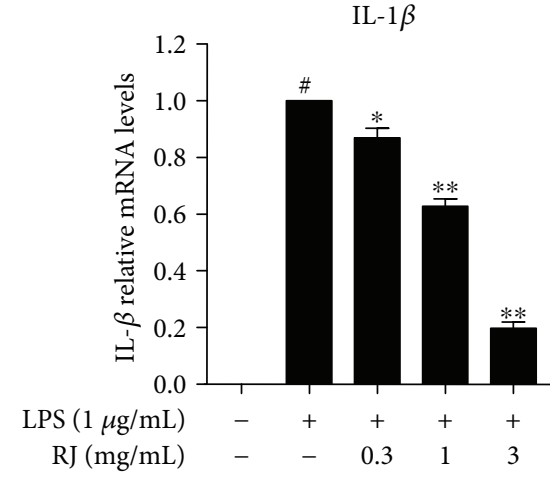

(f)

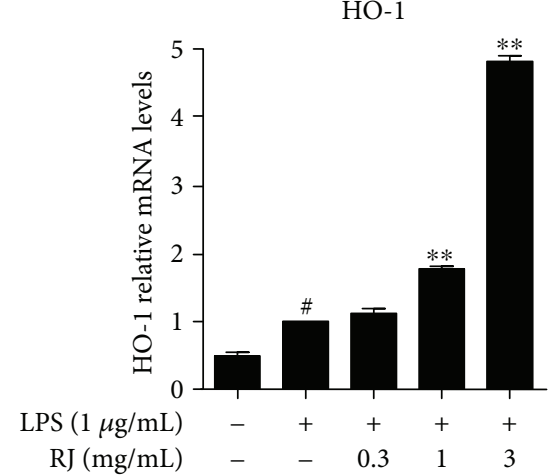

(g)

FIGURE 3: Effects of RJ on LPS-induced mRNA expression of inflammatory mediators in BV-2 microglial cells. BV-2 cells were preincubated in the culture medium with RJ $(0,0.3,1$, and $3 \mathrm{mg} / \mathrm{mL})$ for $1 \mathrm{~h}$ and were then stimulated with $1 \mu \mathrm{g} / \mathrm{mL}$ LPS for another $6 \mathrm{~h}$. BV-2 cells were harvested for RNA extraction with Trizol, and the mRNA expressions of iNOS (a), COX-2 (b), MCP-1 (c), IL-6 (d), TNF- $\alpha$ (e), IL-1 $\beta$ (f), and HO-1 (g) were measured by qRT-PCR. Data are presented as means \pm SEM, and group differences were analyzed by one-way ANOVA with post hoc Tukey's test. ${ }^{\#} P<0.05$ compared with untreated control group; ${ }^{*} P<0.05,{ }^{* *} P<0.01$ compared with the group treated with LPS alone.

could significantly reduce the inflammatory impact of LPS in vitro. Additionally, we demonstrated that RJ displayed excellent anti-inflammatory effects in BV-2 microglial cells via NF- $\kappa \mathrm{B}$, JNK, and p38 signaling pathways.

Microglia, primary immune cells in the brain, are reported to enhance neuroinflammation in most neurodegenerative diseases [40]. Previous study has reported that, in the case of LPS stimulation, BV-2 cells have a similar gene profiling and cytokine secretion functions compared with primary microglia [41]. In addition, another study showed that LPS caused similar effects in BV-2 cells and primary microglia regarding the COX-2 mRNA and protein expression [42]. In this study, we used the BV-2 microglia cell line to assess the effects of RJ on microglia. IL- $1 \beta$, IL- 6 , and TNF- $\alpha$ are three major proinflammatory cytokines during the inflammation process; in our study, $\mathrm{RJ}$ inhibited the transcription of TNF- $\alpha$, IL- $1 \beta$, and IL-6 in a dose-dependent manner, demonstrating the potential of $\mathrm{RJ}$ to protect $\mathrm{BV}-2$ cells against LPS-induced inflammation. In spite of this, our ELISA results, consistent with the qRT-PCR assay, showed 


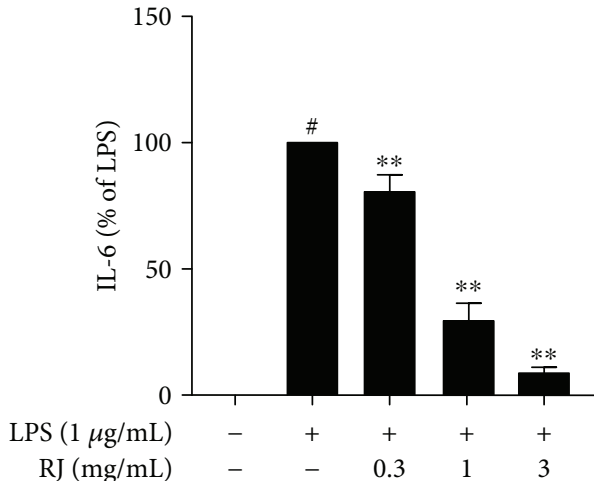

(a)

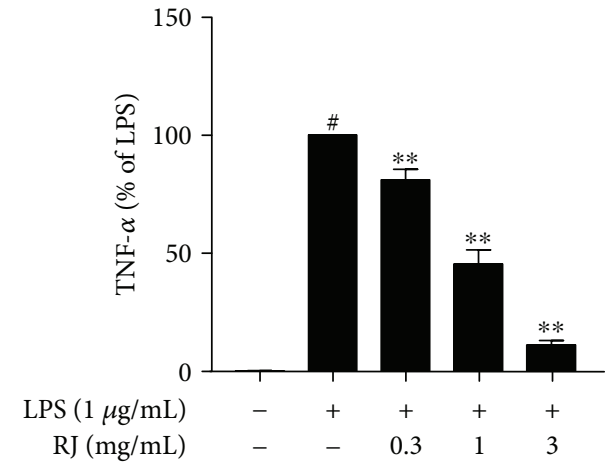

(b)

FIGURE 4: Effects of RJ on LPS-induced cytokine production. BV-2 cells were pretreated with RJ (0, $0.3,1$, and $3 \mathrm{mg} / \mathrm{mL})$ for $1 \mathrm{~h}$, followed by a $24 \mathrm{~h}$ incubation with $1 \mu \mathrm{g} / \mathrm{mL}$ LPS. IL-6 (a) and TNF- $\alpha$ (b) released into the cell culture medium were quantified by ELISA kits. Data are presented as means \pm SEM, and group differences were analyzed by one-way ANOVA with post hoc Tukey's test. ${ }^{\#} P<0.05$ compared with untreated control group; ${ }^{* *} P<0.01$ compared with the group treated with LPS alone.

that RJ treatment under inflammatory conditions also blocked the secretion of proinflammatory mediators, indicating that RJ suppressed the synthesis and release of proinflammatory mediators in $\mathrm{BV}-2$ cells at both transcriptional and translational levels. COX-2 is the rate-limiting enzyme for converting arachidonic acid to proinflammatory prostaglandins, and it plays a pivotal role in chronic and acute inflammation [43]. Our Western blot results indicated that RJ could inhibit COX-2 protein expression in a dose-dependent manner. We also investigated the gene expression of COX-2, the results from which showed that RJ could downregulate the mRNA expression of COX-2, but only $3 \mathrm{mg} / \mathrm{mL}$ of RJ caused a significant decrease. One explanation is that RJ at low concentrations could inhibit the production of COX-2 at translational level, but not at transcriptional level, which means that $\mathrm{RJ}$ at different concentrations will participate in different biological processes. In addition, the effective concentration for RJ to inhibit COX-2 mRNA expression may be relatively higher than that of other mediators, that is, IL-6, IL- $1 \beta$, and TNF- $\alpha$. We used Griess reagent to assess the secretion of NO by BV-2 cells in this study, and the results showed that LPS significantly increased NO production, and RJ at all three different concentrations reversed this situation, illustrating that RJ could improve inflammation caused by excessive NO and that it has a broad therapeutic window against neuroinflammation. LPS treatment in BV-2 cells also caused oxidative stress by increasing ROS levels [44]. Furthermore, the production of ROS could oxidize proteins, lipids, and $\mathrm{DNA}$, and it is considered to be a vital mediator in the AD process [45]. We observed that RJ pretreatment showed significant protective effects in BV-2 cells by scavenging ROS compared to the LPS-treated group, meaning that RJ could work well to maintain cellular redox balance and may inhibit the onset or progress of some oxidative-related diseases, such as neurodegenerative diseases.

It was reported that LPS stimulation induces inflammation by activating NF- $\kappa \mathrm{B}$ and MAPK pathways [46, 47]. Several agents have been previously shown to exert antiinflammatory effects by inhibiting MAPK activation and
DNA binding activity of NF- $\kappa$ B both in RAW 264.7 cells and in microglial BV-2 cells $[48,49]$. In the present study, we explored the signaling-based mechanisms of the antiinflammatory effects of RJ in microglial cells. First, we used LPS at $1 \mu \mathrm{g} / \mathrm{mL}$ to simulate $\mathrm{BV}-2$ cells and observed that the phosphorylation levels of $\mathrm{I} \kappa \mathrm{B} \alpha, \mathrm{JNK}, \mathrm{p} 38$, and ERK peaked at $45 \mathrm{~min}$. However, Jayasooriya et al. reported that the phosphorylation levels of $\mathrm{I} \kappa \mathrm{B} \alpha$ peaked at $30 \mathrm{~min}$ after LPS stimulation in their studies [50]. We speculated that this divergence may be ascribed to different LPS stimulus concentrations or different lineages of BV-2 cells used in our study. Our immunofluorescence assays and Western blot results demonstrated that RJ inhibited the production of inflammatory mediators through NF- $\kappa \mathrm{B}, \mathrm{p} 38$, and JNK pathways. Although LPS significantly activated ERK pathway, it was not suppressed by RJ. According to previous studies, trans10-hydroxy-2-decenoic acid (10-HDA), the major lipid component of RJ, exerts anti-inflammatory effect via the inhibition of LPS-induced NF- $\kappa \mathrm{B}$ activation observed in the murine macrophage cell line RAW 264 [51]. In addition, 10 -HDA could also alleviate inflammation in rheumatoid arthritis synovial fibroblasts through blocking p38 and JNK pathways, but had no effect on ERK activity [52], which was consistent with our Western blot results. Thus, one hypothesis is that $10-\mathrm{HDA}$ is an active component of RJ's anti-inflammatory effect in microglial cells.

HO-1, an antioxidant gene, is related to immunologic defense in immune cells, including BV-2 microglia cells [53]. Previous studies have reported that various compounds exert the anti-inflammatory activity in microglial cells not only through inhibiting NF- $\kappa \mathrm{B}$ pathway, but also through activating Nrf2 pathway and antioxidant response element (ARE), as well as through increasing the synthesis of some antioxidant enzymes, including HO-1 [54, 55]. RJ, according to our results, strikingly upregulated the mRNA expression of HO-1 and also exerted anti-inflammatory effects via NF$\kappa \mathrm{B}$ pathway. Thus, we speculate that the anti-inflammatory effects of RJ may be attributed, at least in part, to the regulatory effects of HO-1. In addition, it would be of great 


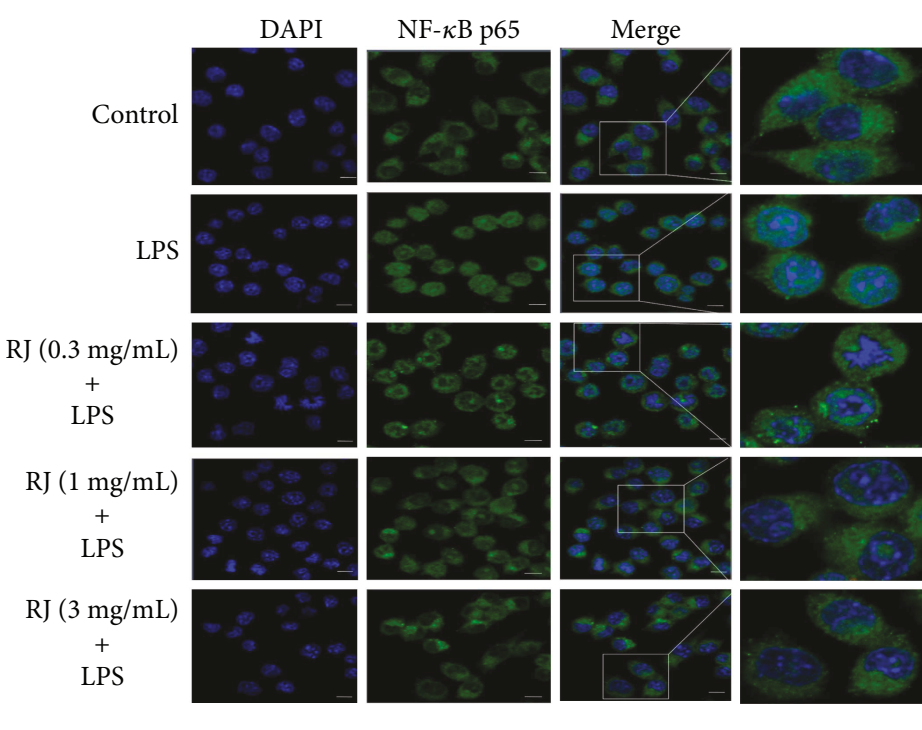

(a)

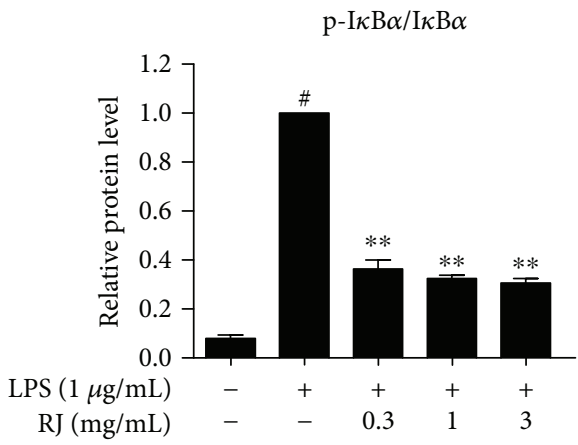

(c)

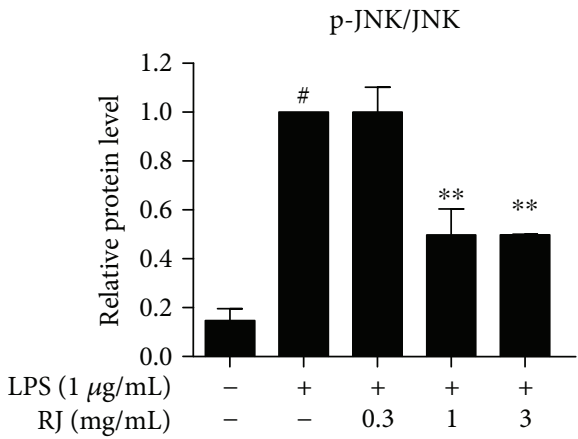

(e)

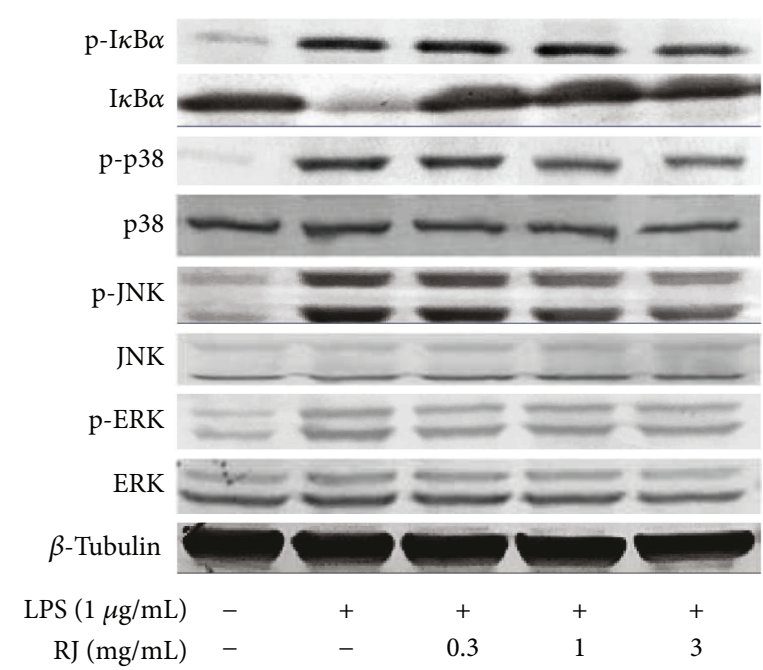

(b)

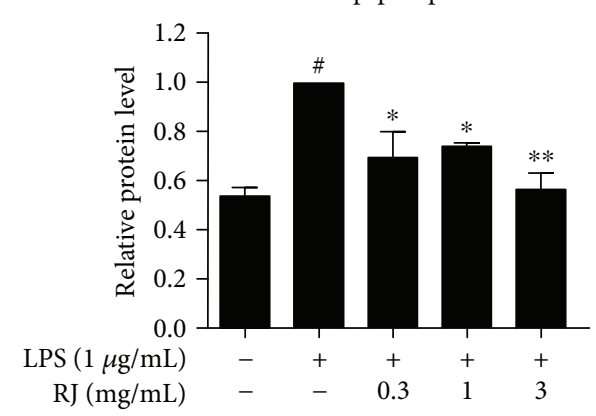

(d)

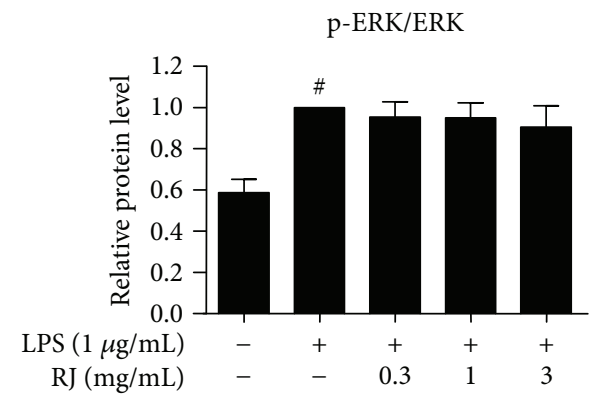

(f)

Figure 5: Effects of RJ on LPS-induced activation of NF- $\kappa$ B and MAPK pathways. BV-2 cells were pretreated with RJ $(0,0.3,1$, and 3 mg/mL) for $1 \mathrm{~h}$, followed by a $45 \mathrm{~min}$ incubation with $1 \mu \mathrm{g} / \mathrm{mL}$ LPS. NF- $\kappa \mathrm{B}$ p 65 nucleus translocation was observed by confocal laser microscope, scale bar $=10 \mu \mathrm{m}$ (a). BV-2 cells were pretreated in the same way as described above. Proteins were extracted, and Western blot analysis was conducted using specific antibodies (b-f). $\beta$-Tubulin protein was used as an internal control. Data are presented as means \pm SEM, and group differences were analyzed by one-way ANOVA with post hoc Tukey's test. ${ }^{\#} P<0.05$ compared with untreated control group; ${ }^{*} P<0.05,{ }^{* *} P<0.01$ compared with the group treated with LPS alone.

significance to explore whether there is an interreaction between NF- $\kappa$ B pathway and Nrf-2 pathway in the next study. In addition, further studies are required to determine the antineuroinflammatory effects of $\mathrm{RJ}$ in animal models.

\section{Conclusion}

In this study, we firstly assessed the anti-inflammatory effects of RJ on LPS-stimulated BV-2 cells and further explored the 
underlying mechanisms. Our results demonstrated that RJ contributed to suppressing inflammatory damage caused by microglial cells and suggested RJ as a promising functional food for delaying inflammatory progress in the future.

\section{Abbreviations}

CNS: $\quad$ Central nervous system

AD: Alzheimer's disease

IL: Interleukin

NGF: $\quad$ Neuron growth factor

LPS: Lipopolysaccharide

NO: $\quad$ Nitric oxide

ROS: $\quad$ Reactive oxygen species

iNOS: Inducible nitric oxide synthase

COX-2: Cyclooxygenase-2

TNF- $\alpha$ : Tumor necrosis factor- $\alpha$

NF- $\kappa$ B: $\quad$ Nuclear factor kappa B

MAPK: Mitogen-activated protein kinases

STAT1: $\quad$ Signal transducer and activator of transcription 1

AP-1: Activator protein

NSAIDs: Nonsteroidal anti-inflammatory drugs

RJ: $\quad$ Royal jelly

HO-1: Heme oxygenase-1

MCP-1: Monocyte chemotactic protein 1

JNK: c-Jun NH2-terminal kinases

ERK: $\quad$ Extracellular signal-regulated kinases

10-HDA: trans-10-hydroxy-2-decenoic acid

ARE: Antioxidant response element.

\section{Conflicts of Interest}

The authors declare no conflict of interests regarding the publication of this paper.

\section{Authors' Contributions}

Meng-Meng You, Yi-Fan Chen, and Kai Wang conceived and designed the experiments; Meng-Meng You, Yi-Fan Chen, and Yong-Ming Pan performed the experiments; Meng-Meng You, Kai Wang, and Yi-Chen Liu analyzed the data; Yong-Ming Pan, Jue Tu, and Yi-Chen Liu contributed to the reagents/materials/analysis tools; Meng-Meng You, Yi-Fan Chen, and Fu-Liang Hu wrote the paper.

\section{Acknowledgments}

The research was supported by the earmarked fund for Modern Agro-industry Technology Research System from the Ministry of Agriculture of China (CARS-44).

\section{Supplementary Materials}

Figure 1: effects of RJ on the phosphorylation levels of $\mathrm{I} \kappa \mathrm{B} \alpha$, ERK, p38, and JNK in LPS-stimulated BV-2 cells at different time points $(\mathrm{A}-\mathrm{E})$. Data are presented as means $\pm \mathrm{SEM}$, and group differences were analyzed by one-way ANOVA with post hoc Tukey's test. ${ }^{\#} P<0.05$ compared with untreated control group; ${ }^{*} P<0.05,{ }^{* *} P<0.01$ compared with the group treated with LPS alone. Figure 2: effects of JNK inhibitor
(SP600125) and p38 inhibitor (SB203580) on the phosphorylation levels of JNK and p38 in LPS-stimulated BV-2 cells. BV-2 cells were pretreated with or without RJ $(3 \mathrm{mg} / \mathrm{mL})$, SP600125 $(20 \mu \mathrm{M})$, or SB203580 $(10 \mu \mathrm{M})$ for $1 \mathrm{~h}$, respectively, then treated with or without LPS for $45 \mathrm{~min}$. The phosphorylated levels of JNK (A) and p38 (B) were detected by Western blot analysis. $\beta$-Tubulin protein was used as an internal control. Data are presented as means \pm SEM, and group differences were analyzed by one-way ANOVA with post hoc Tukey's test. ${ }^{\#} P<0.05$ compared with untreated control group; ${ }^{*} P<0.05,{ }^{* *} P<0.01$ compared with the group treated with LPS alone. (Supplementary Materials)

\section{References}

[1] H. Akiyama, S. Barger, S. Barnum et al., "Inflammation and Alzheimer's disease," Neurobiology of Aging, vol. 21, no. 3, pp. 383-421, 2000.

[2] P. Eikelenboom and F. C. Stam, "Immunoglobulins and complement factors in senile plaques. An immunoperoxidase study," Acta Neuropathologica, vol. 57, no. 2-3, pp. 239-242, 1982.

[3] P. L. McGeer, S. Itagaki, H. Tago, and E. G. McGeer, "Reactive microglia in patients with senile dementia of the Alzheimer type are positive for the histocompatibility glycoprotein HLA-DR," Neuroscience Letters, vol. 79, no. 1-2, pp. 195200, 1987.

[4] J. Rogers, J. Luber-Narod, S. D. Styren, and W. H. Civin, "Expression of immune system-associated antigens by cells of the human central nervous system: relationship to the pathology of Alzheimer's disease," Neurobiology of Aging, vol. 9, no. 4, pp. 339-349, 1988.

[5] J. Ojala, I. Alafuzoff, S. K. Herukka, T. van Groen, H. Tanila, and T. Pirttilä, "Expression of interleukin-18 is increased in the brains of Alzheimer's disease patients," Neurobiology of Aging, vol. 30, no. 2, pp. 198-209, 2009.

[6] M. Pennisi, R. Crupi, R. Di Paola et al., "Inflammasomes, hormesis, and antioxidants in neuroinflammation: role of NRLP3 in Alzheimer disease," Journal of Neuroscience Research, vol. 95, no. 7, pp. 1360-1372, 2017.

[7] S. Mandrekar-Colucci and G. E. Landreth, "Microglia and inflammation in Alzheimer's disease," CNS \& Neurological Disorders Drug Targets, vol. 9, no. 2, pp. 156-167, 2010.

[8] J. Miao, M. Ding, A. Zhang et al., "Pleiotrophin promotes microglia proliferation and secretion of neurotrophic factors by activating extracellular signal-regulated kinase $1 / 2$ pathway," Neuroscience Research, vol. 74, no. 3-4, pp. 269-276, 2012.

[9] R. Tabakman, H. Jiang, I. Shahar, H. Arien-Zakay, R. A. Levine, and P. Lazarovici, "Neuroprotection by NGF in the PC12 in vitro OGD model: involvement of mitogen-activated protein kinases and gene expression," Annals of the New York Academy of Sciences, vol. 1053, no. 1, pp. 84-96, 2005.

[10] M. L. Block, L. Zecca, and J. S. Hong, "Microglia-mediated neurotoxicity: uncovering the molecular mechanisms," Nature Review Neuroscience, vol. 8, no. 1, pp. 57-69, 2007.

[11] L. Qin, X. Wu, M. L. Block et al., "Systemic LPS causes chronic neuroinflammation and progressive neurodegeneration," Glia, vol. 55, no. 5, pp. 453-462, 2007.

[12] P. Parnet, K. W. Kelley, R. M. Bluthé, and R. Dantzer, "Expression and regulation of interleukin-1 receptors in the brain. 
Role in cytokines-induced sickness behavior," Journal of Neuroimmunology, vol. 125, no. 1-2, pp. 5-14, 2002.

[13] Y. E. Kim, C. J. Hwang, H. P. Lee et al., "Inhibitory effect of punicalagin on lipopolysaccharide-induced neuroinflammation, oxidative stress and memory impairment via inhibition of nuclear factor-kappaB," Neuropharmacology, vol. 117, pp. 21-32, 2017.

[14] Y. W. Kwon, S. Y. Cheon, S. Y. Park, J. Song, and J. H. Lee, "Tryptanthrin suppresses the activation of the LPS-treated BV2 microglial cell line via Nrf2/HO-1 antioxidant signaling," Frontiers in Cellular Neuroscience, vol. 11, 2017.

[15] S. T. Dheen, Y. Jun, Z. Yan, S. S. W. Tay, and E. Ang Ling, "Retinoic acid inhibits expression of TNF- $\alpha$ and iNOS in activated rat microglia," Glia, vol. 50, no. 1, pp. 21-31, 2005.

[16] J. Chen, W. Yin, Y. Tu et al., "L-F001, a novel multifunctional ROCK inhibitor, suppresses neuroinflammation in vitro and in vivo: involvement of NF- $\kappa \mathrm{B}$ inhibition and Nrf2 pathway activation," European Journal of Pharmacology, vol. 806, pp. 1-9, 2017.

[17] Y. Hou, G. Li, J. Wang et al., "Okanin, effective constituent of the flower tea Coreopsis tinctoria, attenuates LPS-induced microglial activation through inhibition of the TLR4/NF- $\kappa \mathrm{B}$ signaling pathways," Scientific Reports, vol. 7, article 45705, 2017.

[18] K. W. Zeng, Q. Yu, L. X. Liao et al., “Anti-neuroinflammatory effect of MC13, a novel coumarin compound from condiment Murraya, through inhibiting lipopolysaccharide-induced TRAF6-TAK1-NF- $\kappa$ B, P38/ERK MAPKS and Jak2-Stat1/Stat3 pathways," Journal of Cellular Biochemistry, vol. 116, no. 7, pp. 1286-1299, 2015.

[19] R. Babu, J. H. Bagley, C. Di, A. H. Friedman, and C. Adamson, "Thrombin and hemin as central factors in the mechanisms of intracerebral hemorrhage-induced secondary brain injury and as potential targets for intervention," Neurosurgical Focus, vol. 32, no. 4, p. E8, 2012.

[20] T. S. Hunter, C. Robison, and P. P. Gerbino, "Emerging evidence in NSAID pharmacology: important considerations for product selection," American Journal of Managed Care, vol. 21, no. 7, pp. 139-147, 2015.

[21] I. Carreras, A. C. McKee, J.-K. Choi et al., "R-flurbiprofen improves tau, but not $A \beta$ pathology in a triple transgenic model of Alzheimer's disease," Brain Research, vol. 1541, pp. 115-127, 2013.

[22] M. B. Stokes, P. Sanders, S. J. Nicholls, and P. J. Psaltis, "NSAID use and cardiovascular disease - a cautionary tale," Heart Lung \& Circulation, vol. 26, no. 8, pp. 753-756, 2017.

[23] L. A. García Rodríguez and L. Barreales Tolosa, "Risk of upper gastrointestinal complications among users of traditional NSAIDs and COXIBs in the general population," Gastroenterology, vol. 132, no. 2, pp. 498-506, 2007.

[24] H. J. Yuk, J. W. Lee, H. A. Park et al., "Protective effects of coumestrol on lipopolysaccharide-induced acute lung injury via the inhibition of proinflammatory mediators and NF- $\kappa \mathrm{B}$ activation," Journal of Functional Foods, vol. 34, pp. 181-188, 2017.

[25] W. Zhang, X. Zhang, K. Zou et al., "Seabuckthorn berry polysaccharide protects against carbon tetrachloride-induced hepatotoxicity in mice via anti-oxidative and anti-inflammatory activities," Food \& Function, vol. 8, no. 9, pp. 3130-3138, 2017.

[26] A. G. Sabatini, G. L. Marcazzan, M. F. Caboni, S. Bogdanov, and L. Almeida-Muradian, "Quality and standardisation of royal jelly," Journal of ApiProduct and ApiMedical Science, vol. 1, no. 1, pp. 16-21, 2009.

[27] S. Watanabe, K. Suemaru, K. Takechi, H. Kaji, K. Imai, and H. Araki, "Oral mucosal adhesive films containing royal jelly accelerate recovery from 5 -fluorouracil-induced oral mucositis," Journal of Pharmacological Sciences, vol. 121, no. 2, pp. 110-118, 2013.

[28] P. Fan, B. Han, M. Feng et al., "Functional and proteomic investigations reveal major royal jelly protein 1 associated with anti-hypertension activity in mouse vascular smooth muscle cells," Scientific Reports, vol. 6, no. 1, article 30230, 2016.

[29] G. Elham, N. Vahid, and K. Mozafar, “Antioxidant and protective effects of royal jelly on histopathological changes in testis of diabetic rats," International Journal of Reproductive BioMedicine, vol. 14, no. 8, pp. 519-526, 2016.

[30] J. Pyrzanowska, A. Piechal, K. Blecharz-Klin et al., "Long-term administration of Greek royal jelly improves spatial memory and influences the concentration of brain neurotransmitters in naturally aged Wistar male rats," Journal of Ethnopharmacology, vol. 155, no. 1, pp. 343-351, 2014.

[31] C. C. Chu, S. Y. Chen, C. C. Chyau, and P. D. Duh, “Antiproliferative effect of sweet orange peel and its bioactive compounds against human hepatoma cells, in vitro and in vivo," Journal of Functional Foods, vol. 33, pp. 363-375, 2017.

[32] X. Huang, Y. Zeng, Y. Jiang et al., "Lipopolysaccharide-binding protein downregulates fractalkine through activation of p38 MAPK and NF- $\kappa \mathrm{B}$," Mediators of Inflammation, vol. 2017, Article ID 9734837, 20 pages, 2017.

[33] L. LI, W. LI, S.-W. JUNG, Y.-W. LEE, and Y.-H. KIM, "Protective effects of decursin and decursinol angelate against amyloid $\beta$-protein-induced oxidative stress in the PC12 cell line: the role of Nrf2 and antioxidant enzymes," Bioscience, Biotechnology, and Biochemistry, vol. 75, no. 3, pp. 434-442, 2014.

[34] Y. Zhou, Z. Wu, X. Cao, L. Ding, Z. S. Wen, and J.-S. Bian, "HNO suppresses LPS-induced inflammation in BV-2 microglial cells via inhibition of NF- $\kappa$ B and p38 MAPK pathways," Pharmacological Research, vol. 111, pp. 885-895, 2016.

[35] A. Huante-Mendoza, O. Silva-García, J. Oviedo-Boyso, R. E. W. Hancock, and V. M. Baizabal-Aguirre, "Peptide IDR1002 inhibits NF- $\kappa \mathrm{B}$ nuclear translocation by inhibition of $\mathrm{I} \kappa \mathrm{B} \alpha$ degradation and activates p38/ERK1/2-MSK1-dependent CREB phosphorylation in macrophages stimulated with lipopolysaccharide," Frontiers in Immunology, vol. 7, 2016.

[36] T. Wyss-Coray and L. Mucke, "Inflammation in neurodegenerative disease-a double-edged sword," Neuron, vol. 35, no. 3, pp. 419-432, 2002.

[37] D. Van Dam, K. Coen, and P. P. De Deyn, "Ibuprofen modifies cognitive disease progression in an Alzheimer's mouse model," Journal of Psychopharmacology, vol. 24, no. 3, pp. 383-388, 2008.

[38] M. Ettcheto, E. Sánchez-López, L. Pons et al., “Dexibuprofen prevents neurodegeneration and cognitive decline in APPswe/ PS1dE9 through multiple signaling pathways," Redox Biology, vol. 13, pp. 345-352, 2017.

[39] R. C.-W. Hou, H.-L. Chen, J. T. C. Tzen, and K.-C. G. Jeng, "Effect of sesame antioxidants on LPS-induced NO production by BV2 microglial cells," Neuroreport, vol. 14, no. 14, pp. 1815-1819, 2003.

[40] M. Colonna and O. Butovsky, "Microglia function in the central nervous system during health and neurodegeneration," 
Annual Review of Immunology, vol. 35, no. 1, pp. 441-468, 2017.

[41] A. Henn, S. Lund, M. Hedtjärn, A. Schrattenholz, P. Pörzgen, and M. Leist, "The suitability of BV2 cells as alternative model system for primary microglia cultures or for animal experiments examining brain inflammation," ALTEX, vol. 26 , no. 2 , pp. 83-94, 2009.

[42] K. J. Min, K. Choi, and T. K. Kwon, "Withaferin A down-regulates lipopolysaccharide-induced cyclooxygenase2 expression and PGE2 production through the inhibition of STAT1/3 activation in microglial cells," International Immunopharmacology, vol. 11, no. 8, pp. 1137-1142, 2011.

[43] C. S. Williams, M. Mann, and R. N. DuBois, "The role of cyclooxygenases in inflammation, cancer, and development," Oncogene, vol. 18, no. 55, pp. 7908-7916, 1999.

[44] G. Y. Sun, R. Li, J. Cui et al., "Withania somnifera and its withanolides attenuate oxidative and inflammatory responses and up-regulate antioxidant responses in BV-2 microglial cells," Neuromolecular Medicine, vol. 18, no. 3, pp. 241-252, 2016.

[45] P. Poprac, K. Jomova, M. Simunkova, V. Kollar, C. J. Rhodes, and M. Valko, "Targeting free radicals in oxidative stressrelated human diseases," Trends in Pharmacological Sciences, vol. 38, no. 7, pp. 592-607, 2017.

[46] G. H. Lin, Y. J. Lee, D. Y. Choi et al., “Anti-amyloidogenic effect of thiacremonone through anti-inflamation in vitro and in vivo models," Journal of Alzheimer's Disease, vol. 29, no. 3, pp. 659-676, 2012.

[47] G.-Q. Hou, C. Guo, G.-H. Song et al., "Lipopolysaccharide (LPS) promotes osteoclast differentiation and activation by enhancing the MAPK pathway and COX-2 expression in RAW264.7 cells," International Journal of Molecular Medicine, vol. 32, no. 2, pp. 503-510, 2013.

[48] H. Li, J. H. Yoon, H. J. Won et al., "Isotrifoliol inhibits proinflammatory mediators by suppression of TLR/NF- $\kappa \mathrm{B}$ and TLR/MAPK signaling in LPS-induced RAW264.7 cells," International Immunopharmacology, vol. 45, pp. 110-119, 2017.

[49] B. Hui, L. Zhang, Q. Zhou, and L. Hui, "Pristimerin inhibits LPS-triggered neurotoxicity in BV-2 microglia cells through modulating IRAK1/TRAF6/TAK1-mediated NF- $\kappa$ B and AP1 signaling pathways in vitro," Neurotoxicity Research, vol. 33, no. 2, pp. 268-283, 2018.

[50] R. G. P. T. Jayasooriya, K.-T. Lee, H.-J. Lee, Y. H. Choi, J.W. Jeong, and G.-Y. Kim, "Anti-inflammatory effects of $\beta$ hydroxyisovalerylshikonin in BV2 microglia are mediated through suppression of the PI3K/Akt/NF-kB pathway and activation of the Nrf2/HO-1 pathway," Food and Chemical Toxicology, vol. 65, pp. 82-89, 2014.

[51] T. Sugiyama, K. Takahashi, S. Tokoro, T. Gotou, P. Neri, and H. Mori, "Inhibitory effect of 10-hydroxy-trans-2-decenoic acid on LPS-induced IL- 6 production via reducing $\mathrm{I} \kappa \mathrm{B}-\zeta$ expression," Innate Immunity, vol. 18, no. 3, pp. 429-437, 2011.

[52] X.-Y. Yang, D.-s. Yang, Wei-Zhang et al., "10-Hydroxy-2decenoic acid from royal jelly: a potential medicine for RA," Journal of Ethnopharmacology, vol. 128, no. 2, pp. 314-321, 2010.

[53] A. Jazwa and A. Cuadrado, "Targeting heme oxygenase-1 for neuroprotection and neuroinflammation in neurodegenerative diseases," Current Drug Targets, vol. 11, no. 12, pp. 1517-1531, 2010.
[54] G. Y. Sun, Z. Chen, K. J. Jasmer et al., "Quercetin attenuates inflammatory responses in BV-2 microglial cells: role of MAPKs on the Nrf2 pathway and induction of heme oxygenase-1," PloS One, vol. 10, no. 10, article e0141509, 2015.

[55] C. H. Kang, Y. H. Choi, S. K. Moon, W. J. Kim, and G. Y. Kim, "Quercetin inhibits lipopolysaccharide-induced nitric oxide production in BV2 microglial cells by suppressing the NF- $\kappa \mathrm{B}$ pathway and activating the Nrf2-dependent HO-1 pathway," International Immunopharmacology, vol. 17, no. 3, pp. 808813, 2013. 


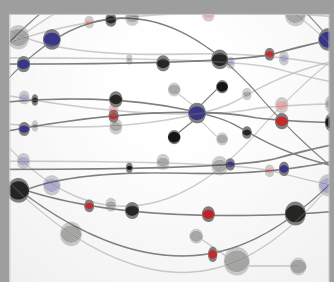

The Scientific World Journal
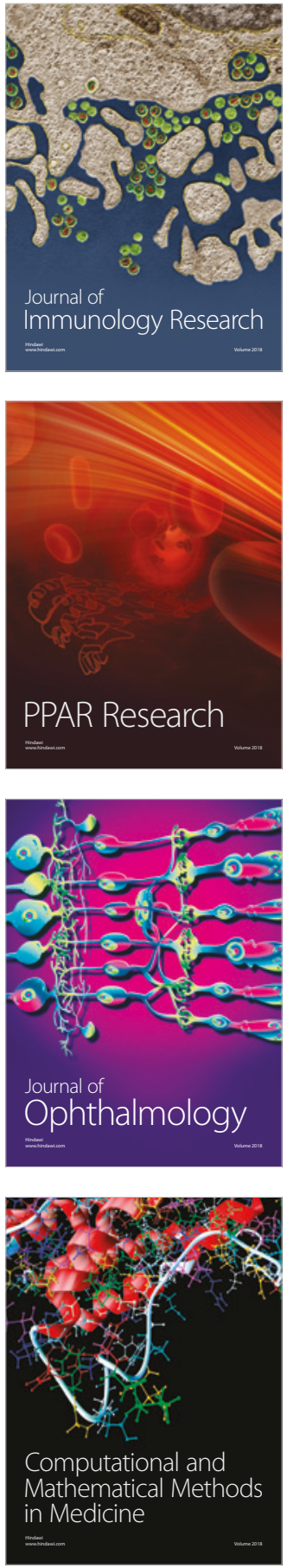

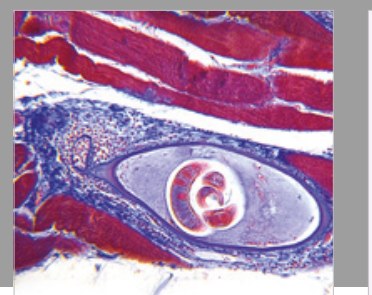

Gastroenterology Research and Practice

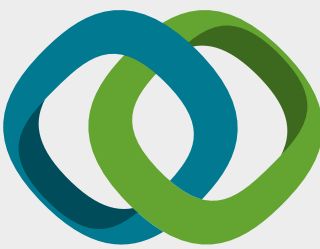

\section{Hindawi}

Submit your manuscripts at

www.hindawi.com
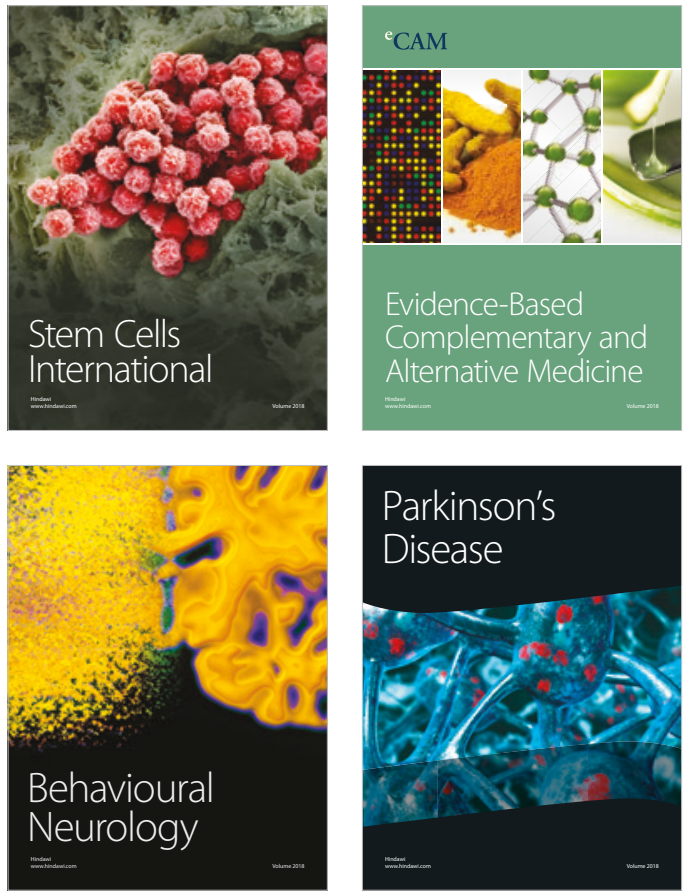

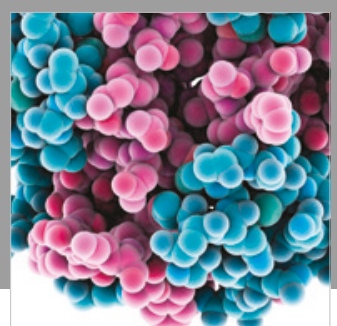

ournal of

Diabetes Research

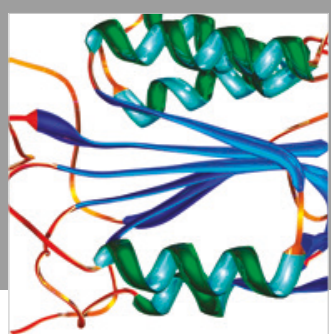

Disease Markers
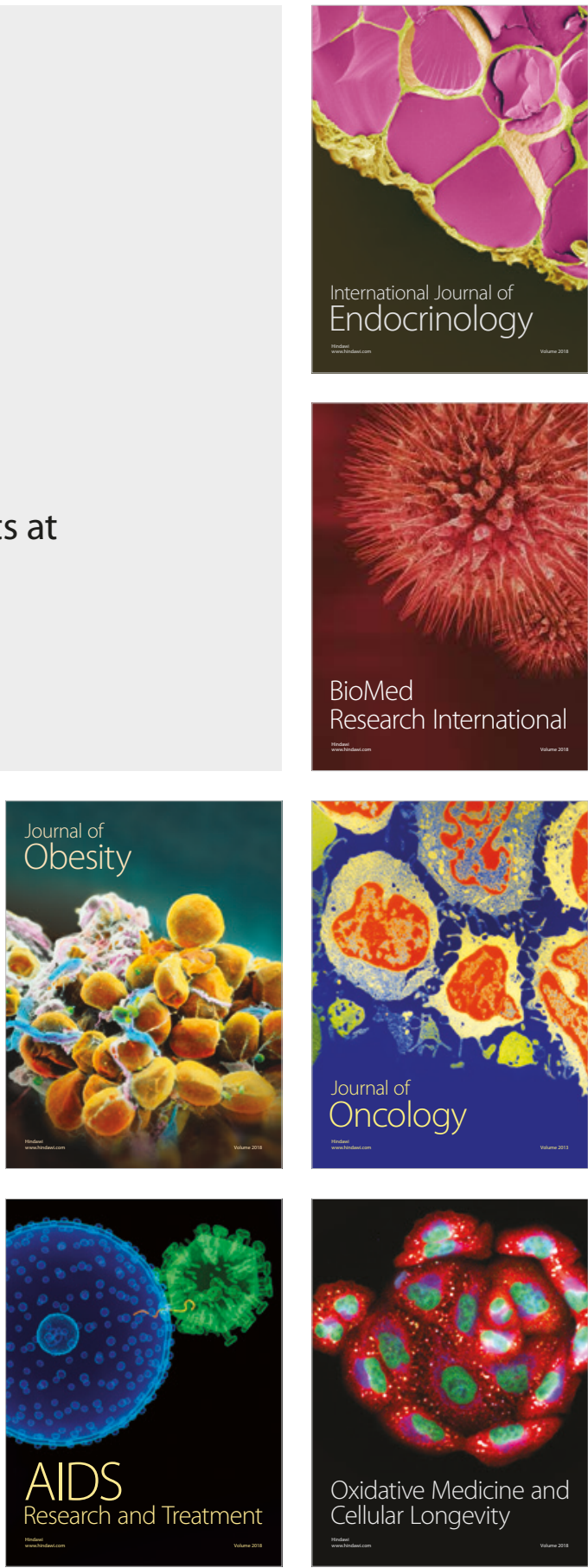